\title{
Participation of microRNA-34a/RANKL in the osteogenic potential of the Poly(vinylidene- trifluorethylene)/barium titanate membrane
}

Helena Bacha Lopes ${ }^{1}$, Emanuela Prado Ferraz ${ }^{1}$, Adriana Luisa Gonçalves de Almeida ${ }^{1}$, Rodrigo Paolo Flores Abuna ${ }^{1}$, Mohammad Quamarul Hassan ${ }^{2}$, Adalberto Luiz Rosa ${ }^{1}$, Marcio Mateus Beloti ${ }^{1}$

${ }^{1}$ Cell Culture Laboratory, School of Dentistry of Ribeirão Preto, University of São Paulo, Brazil

2 Department of Oral and Maxillofacial Surgery, School of Dentistry, University of Alabama at Birmingham, USA

E-mail: abuna@usp.br

\section{Purpose of Study}

The aim of this study was to investigate a possible mechanism involving miRs and RANKL in the osteogenic potential of the Poly(vinylidene-trifluoroethylene)/barium titanate composite membrane (PVDF) .

\section{Background}

Barrier membranes have been extensively used in dentistry to prevent soft tissue down-growth into the bone defects and to promote alveolar ridge augmentation. Previous studies of our group showed that the PVDF enhances both the in vitro osteoblastic differentiation and the in vivo bone repair compared with a commercially available polytetrafluoroethylene (PTFE) membrane.

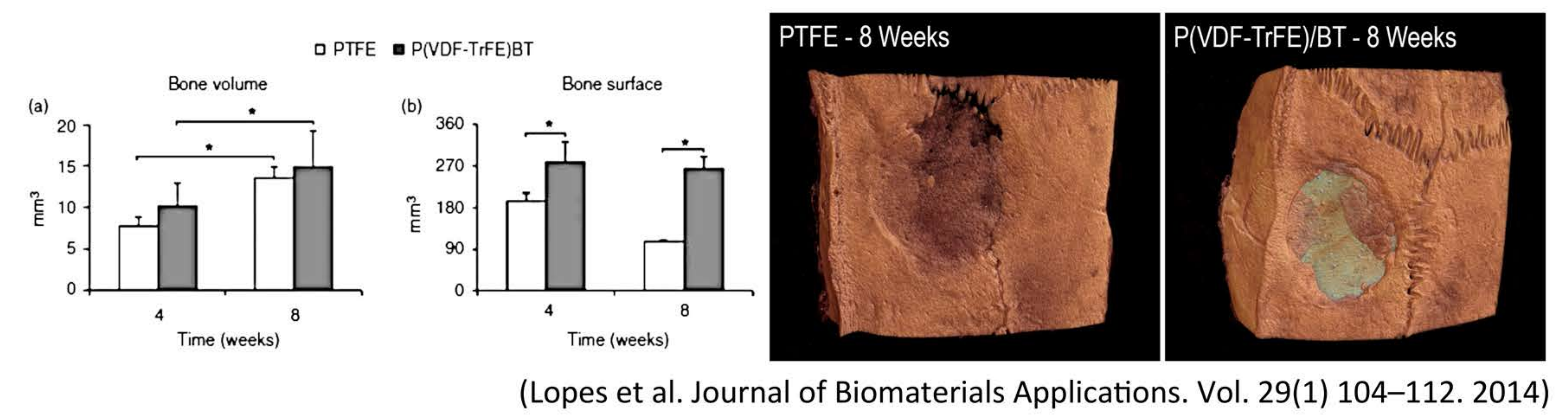

\section{Experimental Procedure}

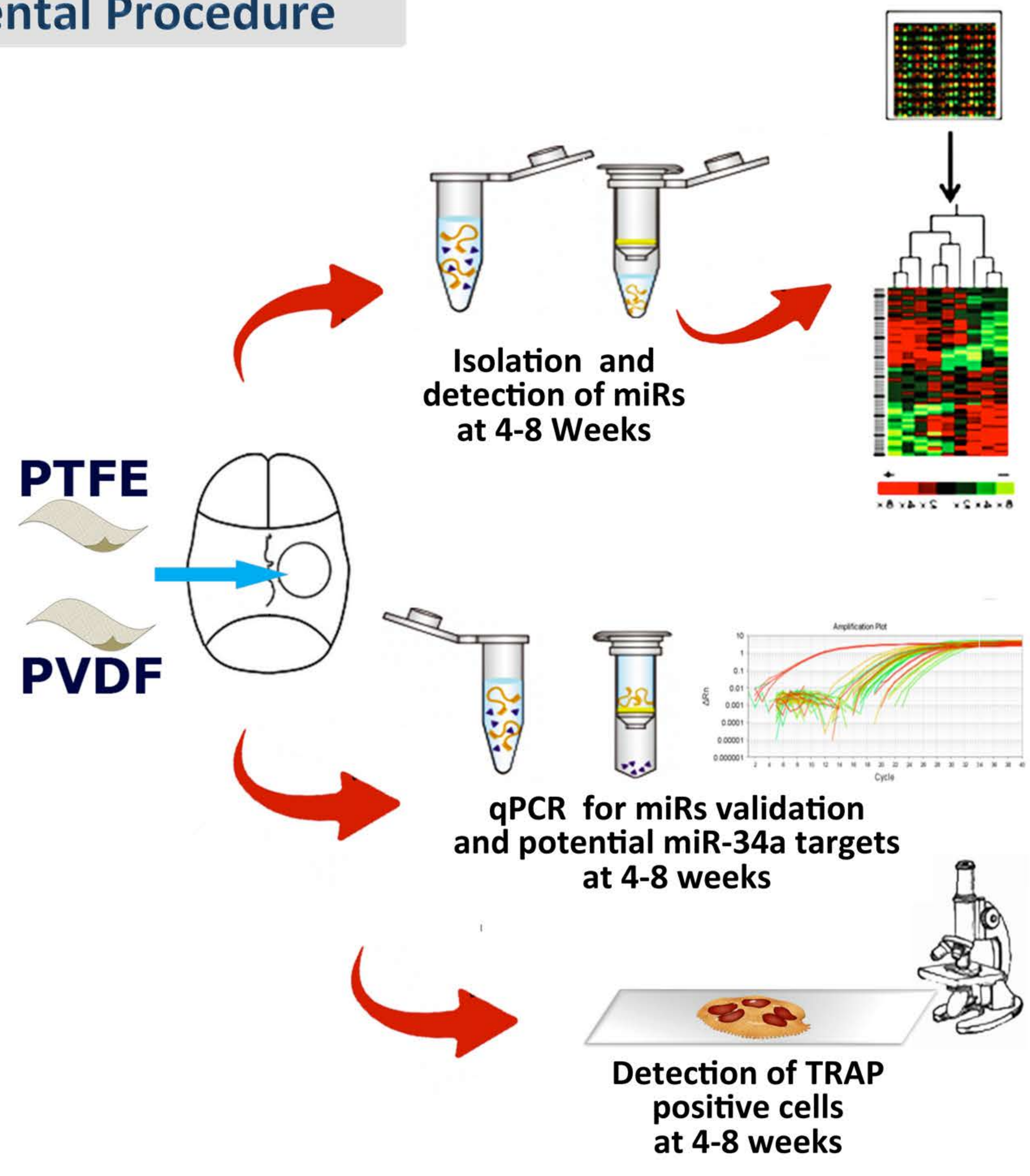

\section{Concluding Remark}

PVDF membrane induces higher bone repair, at least in part, by triggering an intracellular mechanism of miR-34a upregulation/RANKL dowregulation loop, which inhibits osteoclastic activity.

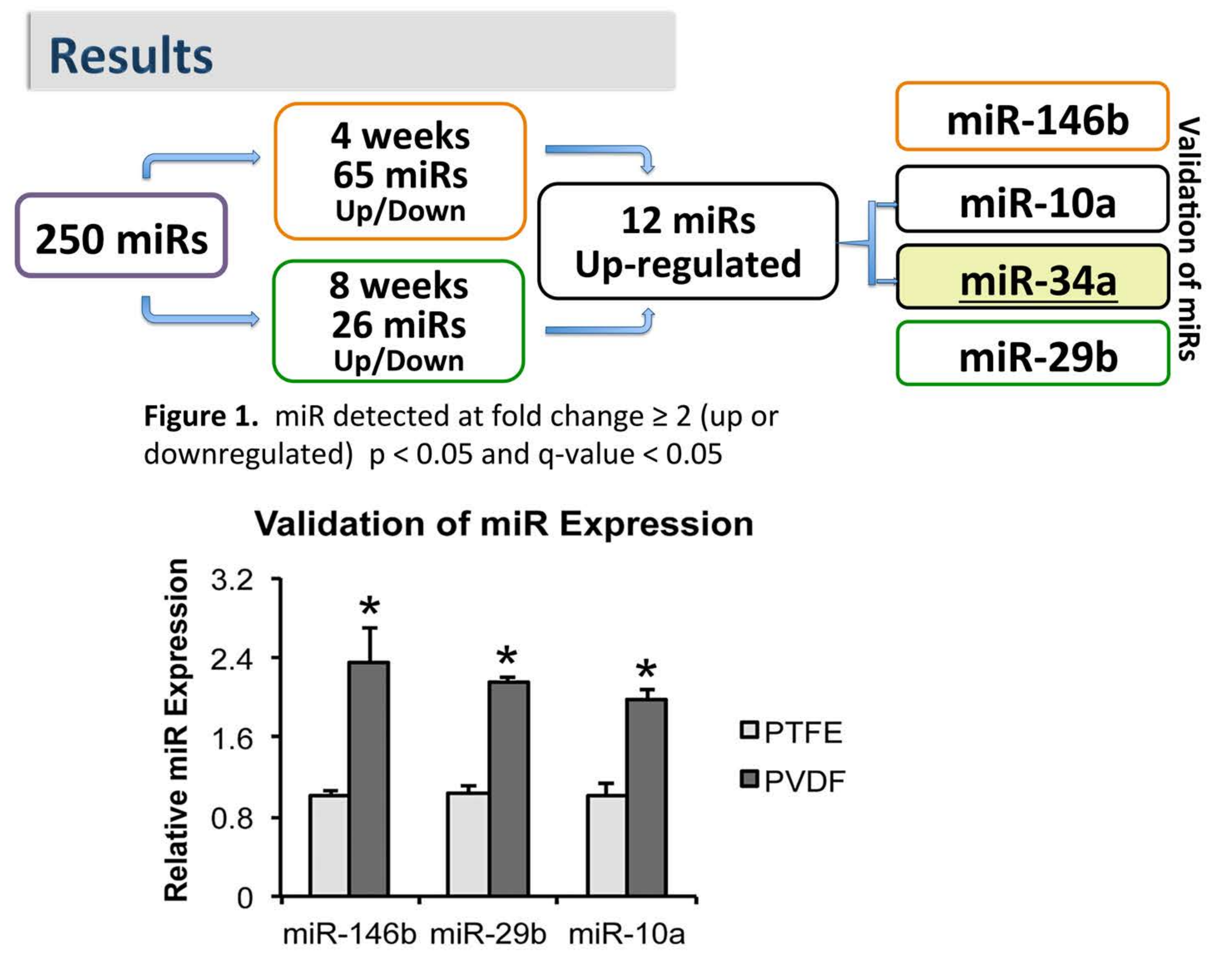

Figure 2. Expression of miR-146b at 4 weeks, and miR-29b and $-10 a$ at 8 weeks. ${ }^{*}$ indicate statistical significant difference $(p \leq 0.05)$.
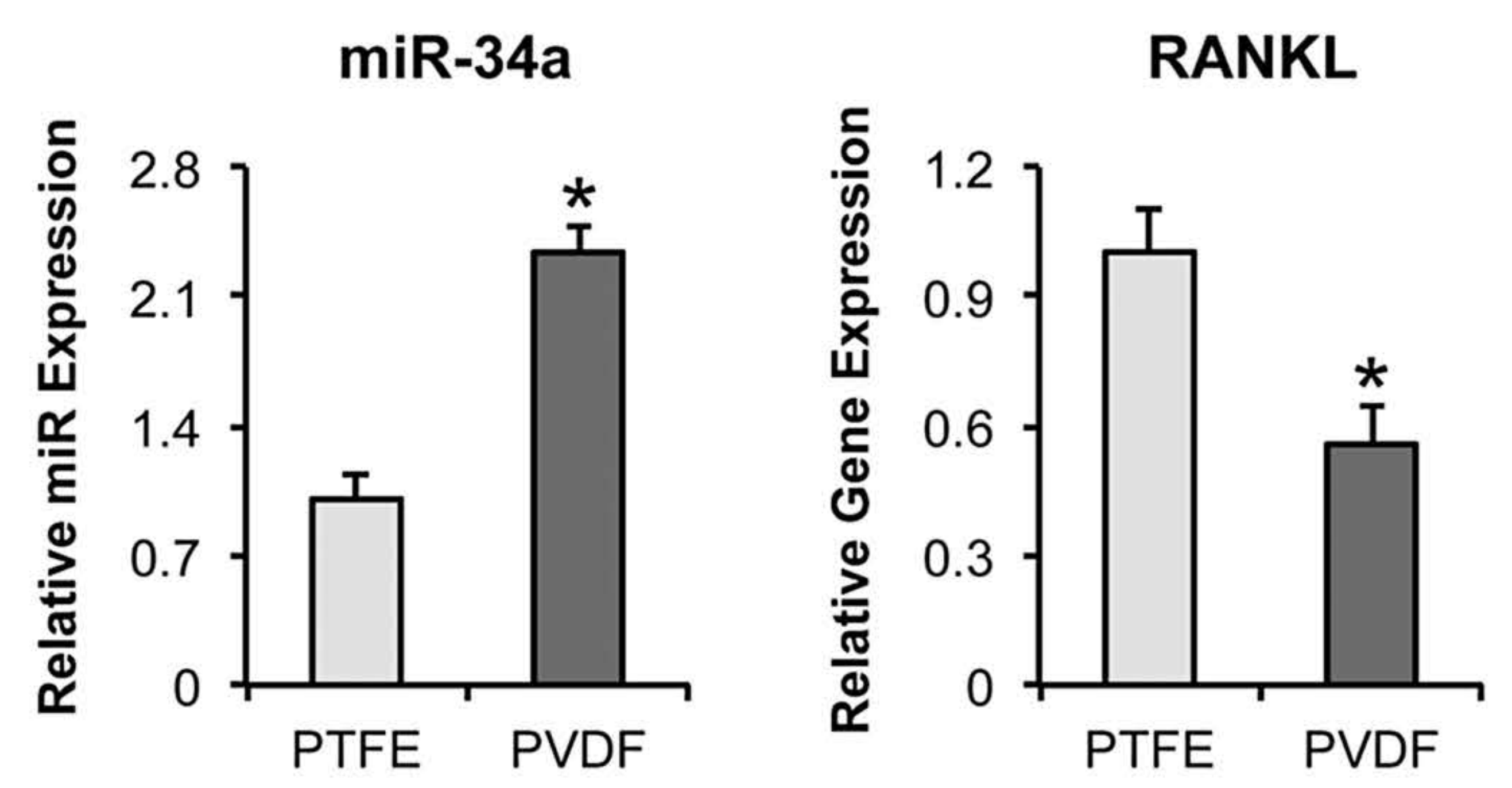

Figure 3. Expression of miR-34a and RANKL at 8 weeks.

$*$ indicate statistical significant difference $(\mathrm{p} \leq 0.05)$.
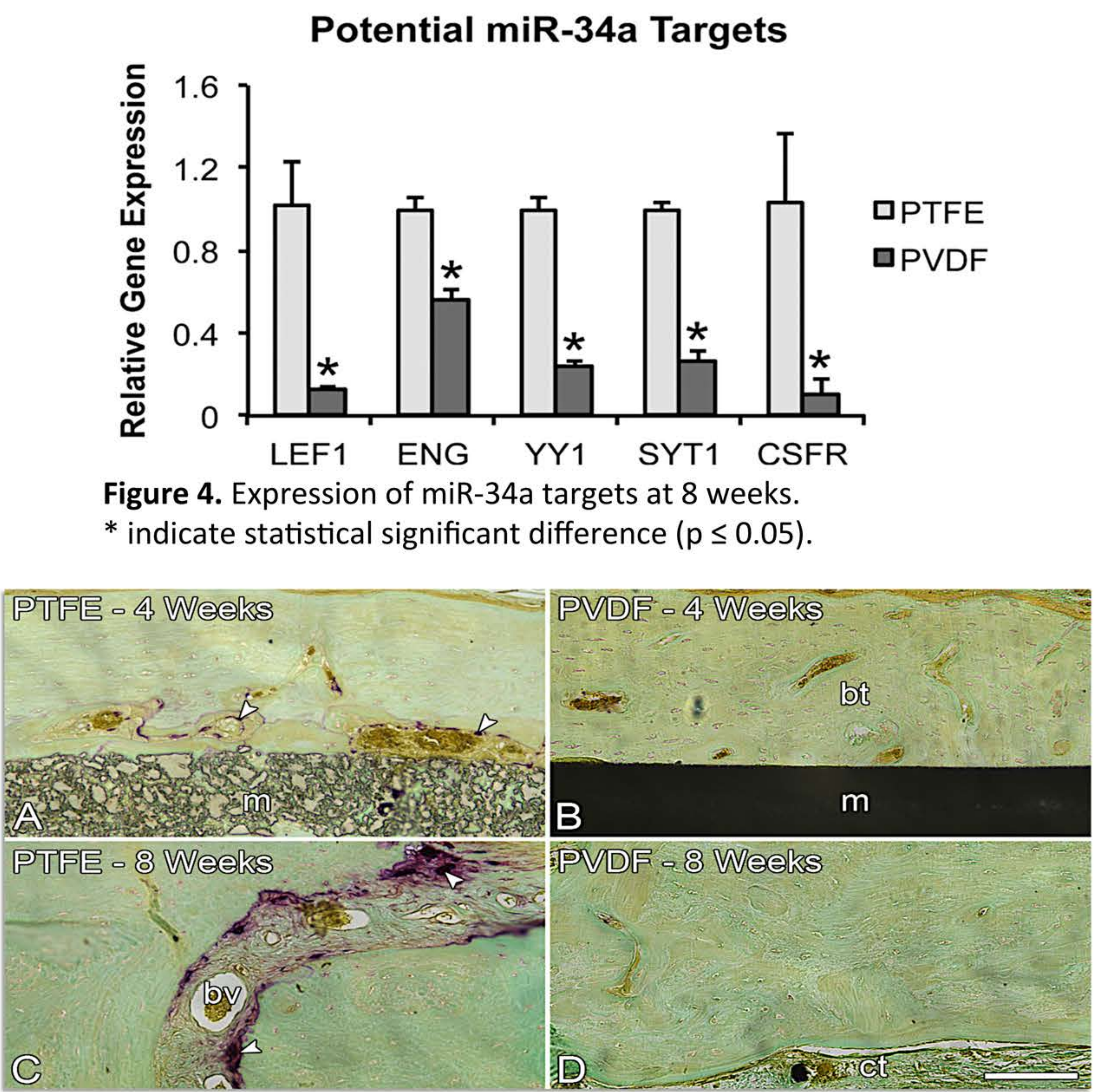

Figure 5. Light microscopy of rat calvarial bone defects implanted with (PTFE; $A$ and $C$ ) or (PVDF, B and D) membrane at 4 ( $A$ and $B$ ) and 8 (C and D). bt: bone tissue; bv: blood vessel; ct: connective tissue; $\mathrm{m}$ : membrane. Scale bar: $A-D=100 \mu \mathrm{m}$. 